IZA DP No. 5051

Interactions between Local and Migrant Workers at the Workplace

Gil S. Epstein

Yosef Mealem

July 2010 


\title{
Interactions between Local and Migrant Workers at the Workplace
}

\author{
Gil S. Epstein \\ Bar-Ilan University, \\ CReAM and IZA \\ Yosef Mealem \\ Netanya Academic College \\ Discussion Paper No. 5051 \\ July 2010 \\ IZA \\ P.O. Box 7240 \\ 53072 Bonn \\ Germany \\ Phone: +49-228-3894-0 \\ Fax: +49-228-3894-180 \\ E-mail: iza@iza.org
}

Any opinions expressed here are those of the author(s) and not those of IZA. Research published in this series may include views on policy, but the institute itself takes no institutional policy positions.

The Institute for the Study of Labor (IZA) in Bonn is a local and virtual international research center and a place of communication between science, politics and business. IZA is an independent nonprofit organization supported by Deutsche Post Foundation. The center is associated with the University of Bonn and offers a stimulating research environment through its international network, workshops and conferences, data service, project support, research visits and doctoral program. IZA engages in (i) original and internationally competitive research in all fields of labor economics, (ii) development of policy concepts, and (iii) dissemination of research results and concepts to the interested public.

IZA Discussion Papers often represent preliminary work and are circulated to encourage discussion. Citation of such a paper should account for its provisional character. A revised version may be available directly from the author. 
IZA Discussion Paper No. 5051

July 2010

\section{ABSTRACT \\ Interactions between Local and Migrant Workers at the Workplace ${ }^{\star}$}

In this paper we consider the interaction between local workers and migrants in the production process of a firm. Both local workers and migrants can invest effort in assimilation activities in order to increase the assimilation of the migrants into the firm and thereby increase their interaction and production activities. We consider the effect of the relative size (in the firm) of each group and the cost of activities on the migrants' assimilation process.

JEL Classification: D74, F230, I20, J61, L140

Keywords: assimilation, contracts, ethnicity, market structure, networks, harassment

Corresponding author:

Gil S. Epstein

Department of Economics

Bar-Ilan University

52900 Ramat-Gan

Israel

E-mail: epsteig@mail.biu.ac.il

\footnotetext{
* Financial support from the Adar Foundation of the Economics Department of Bar-llan University is gratefully acknowledged.
} 


\section{Introduction}

Studies of minorities around the world show, with few exceptions, that they tend to earn wages substantially below those of comparable general workers (Altonji and Blank 1999, Blau and Kahn, 2006, 2007, Bhaumik, Gang and Yun, 2006). In part, this reflects a failure on the part of the minority group to undertake the effort to assimilate (Constant, Gataullina and Zimmermann, 2008). This failure can be caused in the face of high adjustment costs, such as inadequate language skills, intergenerational familial conflicts, and, in the case of immigrants, lack of knowledge about the host country's labor market (Chiswick and Miller, 1995, 1996, Bauer, Epstein and Gang, 2005, Epstein and Gang, 2009). On occasion, minority workers out preform the other workers (Chiswick, 1977, Deutsch, Epstein and Lecker, 2006).

Efforts of the migrants to assimilate and efforts by the local population to accept them and to bring them into line with the local population are made. Often, the locals are less than welcoming, blaming the newcomers for depressing wages and displacing current workers - i.e., causing unemployment. This presumption has very strong policy implications and is implicit, for example, in the calls for increased regulations about immigration that are heard worldwide. Yet, there is mixed evidence about the impact of minorities on wages and employment - it depends on whether they are substitutes or complement the current workers, with respect to the skills and other attributes which they bring to the labor market (Gang and Rivera-Batiz 1994, Gang, Rivera-Batiz and Yun 2002). Whether minorities actually lower wages and increase employment or not, the perception exists that they do. Because of this perception the majority may take active steps to discourage minority assimilation discrimination, isolation, and so on (see Epstein and Gang, 2006, 2009).

Often the efforts of both parties are mediated through political institutions. These institutions exist in both the minority and majority worlds. They could be, for example, political parties, trade organizations, unions, or thugs. These are organizations which are able to overcome the free-rider problems individual members of each group have, in moving from the actions they desire to take, to actually taking them.. Yet, while an organization's purpose may be to represent the members of their group, the interests' of the organization and that of its members do no always coincide (see, for example, Alesina and La Ferrara, 2000, Anas, 2002, Dustmann, Fabbri and Preston, 2004, Kahanec, 2006, Lazear, 1999 and Epstein and Gang, 2009). 
We are interested in why minorities are so often at a disadvantage relative to the majority. Assimilation efforts by the minority and the local population are elements which determine how well the minority does in comparison to the local population. We examine the consequences of increases in the numbers migrants, the local population and the relationship in the production function of the firm where both work. We construct a model in which there are two actors: the local working population and the migrants working at the same firm and their interaction within the firm, in terms of production.

Our study shows that the structure of the firm, the number of migrants and local population are curtailed for the assimilation process. Moreover the cost of investment is an important component and can be affected by incentives made by the employer or public policy. More specifically, we show that increasing the number of migrants in a certain firm will decrease the investment in assimilation activities by all workers both local and migrants. In general, we show that it is better for both the local worker and the migrant when the local workers will be in separate firms. However this is not always the case and many firms with migrants and locals working together exist. In this paper we consider the effects the size of the population of migrants and local workers have on the assimilation efforts of both types of workers. We also consider the effect the cost of investment in assimilation activities has on the assimilation process of the migrants in the firm.

\section{The Model}

Consider a firm which has both locals $L(L>1)$, and migrants., (foreign workers), $F$ $(F>1)$. For simplicity, we assume that there is only one group of migrants. The efficiency/productivity level of the local workers and the migrants may not be identical. We normalize the efficiency level of local population workers to unity. The migrants' productive/efficiency level depends on two main factors: 1. the investment made by the migrant to assimilate, $a$, and 2. the effort invested by local worker to help the migrant assimilate into the working place, $b$. We assume that the production function has the following form: 


$$
X=f[L \underbrace{F\left(\frac{a+b L^{\alpha}+1}{\beta}\right)}_{G}]
$$

where $G=F\left(\frac{a+b L^{\alpha}+1}{\beta}\right)$ is the effectiveness of $F$ migrant workers. Let us explain this further. To assimilate one migrant worker each migrant invest $a$ units for himself and each local worker invests $b$ units. $b L^{\alpha}$ means that, despite the fact that each local worker invests $b$ units in one migrant worker, the impact of $L$ local workers on the assimilation of one migrant worker equals to $b L^{\alpha}$. Note that $\alpha>0$ is a marginal effect that $L$ local workers have on the effective number of migrant workers. As $\alpha$ increases the local workers have a stronger impact on the assimilation of the migrants. If both the local workers and the migrants do not invest efforts for the assimilation of the migrants, the effectiveness of one migrant worker equals to $\frac{1}{\beta}$. Thus the effectiveness of $F$ migrants will equal to: $\left(\frac{a+b L^{\alpha}+1}{\beta}\right)$. Therefore the term $G=F\left(\frac{a+b L^{\alpha}+1}{\beta}\right)$ represents the effective number of migrants working. It is assumed that the production function has decreasing returns to scale and satisfies $f_{G}>0, f_{L}>0, f_{G G}<0, f_{L L}<0$.

Let us consider a representative of the local workers and of the migrants. Each representative determines the optimal effort invested in the assimilation process. We assume that there is no free-riding and each worker invests according to the investment of the representative worker of their group. Denote by $c$ the cost of investing one unit to assimilate by the migrant. $d$ is the ratio between the costs of investment of the local worker and the migrant for each unit invested. Thus, the cost of one unit invested by the local worker equals: $c d$. For $d=1$ the cost of investment by the local worker and the migrant are identical. If $d$ is smaller (greater) than the unit, the cost for the migrant is higher (lower) than that of the local worker. Since each local worker invests $b$ units to help each migrant assimilate, the total effort invested by a local worker for $F$ migrants would be $b F$. 
It is assumed that the utility each worker obtains equals their wages (equaling the marginal productivity) minus the cost of investing in assimilation activities. The utility of a representative migrant will equal :

$$
U^{F}=f_{G}\left(\frac{a+b L^{\alpha}+1}{\beta}\right)-c a
$$

The utility of a representative local worker will equal:

$$
U^{L}=f_{L}+\frac{f_{G} \alpha b L^{\alpha-1} F}{\beta}-d c b F
$$

Both the migrant and the local worker determine their investment in assimilation activities by maximizing the utility. The first order conditions for maximization of the utility of both the migrants and the local works with respect to $a$ and $b$ are given by:

$$
U_{a}^{F}=\frac{f_{G}}{\beta}+\frac{f_{G G} F\left(a+b L^{\alpha}+1\right)}{\beta^{2}}-c=0
$$

and

$$
U_{b}^{L}=\frac{f_{L G} L^{\alpha} F}{\beta}+\frac{f_{G} \alpha L^{\alpha-1} F}{\beta}+\frac{f_{G G} \alpha b L^{2 \alpha-1} F^{2}}{\beta^{2}}-d c F=0
$$

We assume that the second order conditions hold ${ }^{2}$

Denote by $a^{*}$ and $b^{*}$ the optimal investment in assimilation activities invested by the foreign workers and the local workers respectively (thus $a^{*}$ and $b^{*}$ are the outcome of the first order condition defined in (4) and (5)).

2 The second order condition must satisfy: $U_{a a}^{F}=\frac{2 f_{G G} F}{\beta^{2}}+\frac{f_{G G G} F^{2}\left(a+b L^{\alpha}+1\right)}{\beta^{3}}<0$, $U_{b b}^{L}=\frac{f_{L G G} L^{2 \alpha} F^{2}}{\beta^{2}}+\frac{2 f_{G G} \alpha L^{2 \alpha-1} F^{2}}{\beta^{2}}+\frac{f_{G G G} \alpha b L^{3 \alpha-1} F^{3}}{\beta^{3}}<0 . \quad$ Given $\quad$ this the Hessian $H=\frac{f_{G G G} f_{G G} \alpha L^{2 \alpha-1} F^{4}\left(a+b L^{\alpha}+1\right)}{\beta^{5}}+\frac{2\left(f_{G G}\right)^{2} \alpha L^{2 \alpha-1} F^{3}}{\beta^{4}}$ is positive since we assume $U_{a a}^{F}<0$ and $f_{G G}<0$. If we assume that $f_{G G G}=f_{L G G}=f_{L L G}=0$ then the second order conditions hold. We will be making this assumption latter on in the paper. 
Let us now consider how the investment, of the different type of workers, changes the differing parameters which identify both the production and the cost functions.

We start by considering how a change in the number of migrants in the firm affects their own investment to assimilate.

$$
\frac{\partial a^{*}}{\partial F}=-\frac{a^{*}+1}{F}<0
$$

This result states that increasing the number of migrants decreases the investment of each worker in assimilation activities.

The reason for this result is twofold: 1. increasing the number of migrants, against the number of local workers, increases the proportion of immigrants in the firm and, as a result, the assimilation is not so curtailed with respect to production and wages, and 2. the total effect of assimilation affects the activities of the migrants, thus, as their numbers increase, each can decrease his/her efforts but the total investment could still increase. $^{3}$

We would thus expect to see firms, with a large number of migrants, investing less effort in assimilation activities than a firm with a small number of migrants. A policy implication, in this case, could be to divide the migrants into as many firms as possible, in order to increase assimilation.

Let us now consider how an increase in the number of migrants affects the investment of the local population. We can verify that,

$$
\frac{\partial b^{*}}{\partial F}=-\frac{b^{*}}{F}<0
$$

This result states that increasing the number of migrants decreases the local workers' investment in each of the migrants.

\footnotetext{
${ }^{3}$ On different aspects of the optimal size of minorities and the size affect on society, see Gradstein and Schiff (2006) and Gradstein and Justman (2005) and Rapoport and Weiss (2003)
} 
The main reason for this result is that increasing the number of migrants increases the local workers' marginal investment cost. This is true since each local worker invests efforts in assimilating each migrant and thus increases their marginal investment cost. Increasing the marginal cost decreases the investment in each migrant.

Let us now consider how an increase in the number of migrants affects the total investment made by each party: $\left(a^{*} F+L b^{*} F\right)$. We can see that $\frac{\partial\left(a^{*} F\right)}{\partial F}=-1$ and $\frac{\partial\left(L b^{*} F\right)}{\partial F}=L \frac{\partial\left(b^{*} F\right)}{\partial F}=0$, which means that increasing $F$ would decrease the total effort made by the migrants (the elasticity of $a$ with respect to $F$ is $\left.\frac{\partial a^{*}}{\partial F} \frac{F}{a^{*}}=-\left(\frac{a^{*}+1}{a^{*}}\right)<-1\right)$ but the total investment the local workers (or worker) invests in all the migrants is unchanged (the elasticity of $b$ with respect to $F$ is $\left.\frac{\partial b^{*}}{\partial F} \frac{F}{b^{*}}=-1\right)$.

Thus, even though the effort invested by the migrants may decrease, the total investment of the local population will not change. However the effect it has on each migrant will decrease, since the number of migrants has increased.

Given that the third derivatives equal or are close to zero $f_{G G G}=f_{L G G}=f_{L L G}=0^{4}$ (see Epstein and Gang, 2009 ) we obtain that the effect of a change in the number of local workers on the assimilation of the migrants and local workers can be written as follows: ${ }^{5}$

${ }^{4}$ Since $f_{G G}<0$ the second order conditions hold: $U_{a a}^{F}=\frac{2 f_{G G} F}{\beta^{2}}<0, U_{b b}^{L}=\frac{2 f_{G G} \alpha L^{2 \alpha-1} F^{2}}{\beta^{2}}<0$ and the Hessian $H=\frac{2\left(f_{G G}\right)^{2} \alpha L^{2 \alpha-1} F^{3}}{\beta^{4}}$ is positive.

${ }^{5}$ When the third derivatives do not equal zero we get:

$$
\left[\frac{f_{L G} L^{2 \alpha-1} F}{\beta}+\frac{f_{L L G} L^{2 \alpha} F}{\beta}+d c L^{\alpha-1} F(\alpha-1)\right] U_{a a}^{F}-\frac{f_{L G G} F(a+1)}{\beta^{2}} U_{b b}^{L}
$$

$\frac{\partial a^{*}}{\partial L}=\frac{+\left[\frac{f_{G G G} \alpha L^{2 \alpha-1} F^{3}(a+1)}{\beta^{4}}-\frac{f_{L G G} L^{2 \alpha} F^{2}}{\beta^{3}}\right]\left[f_{L G}+\frac{f_{L G G} b L^{\alpha} F}{\beta}\right]}{H}$ and 


$$
\frac{\partial a^{*}}{\partial L}=\frac{\left[f_{L G} L^{\alpha}+\beta d c(\alpha-1)\right] F L^{\alpha-1} U_{a a}^{F}}{\beta H}
$$

and

$$
\frac{\partial b^{*}}{\partial L}=\frac{\left(-\frac{\alpha f_{G G} F}{L \beta^{2}}\right)\left[4 L^{\alpha-1} F(\alpha-1)\left(c-\frac{f_{G G} F(a+1)}{\beta^{2}}\right)+\frac{2 f_{G G} b L^{2 \alpha-1} F^{2}}{\beta^{2}}+\frac{f_{L G} L^{\alpha} F}{\beta}\right]}{H}
$$

From (10) we can see that increasing the number of local workers in the firm will decrease their efforts $\left(\frac{\partial b^{*}}{\partial L}<0\right)$ if the two categories of workers are rivals, $f_{L G}<0$, and the marginal effect of $L$ local workers on the effective number of migrant workers is less than one, $\alpha<1$. Let us explain this result. If the two groups of workers are rivals, $f_{L G}<0$, then increasing $L$ will decrease the marginal productivity of the effective migrant worker ( $f_{G}$ decreases) but on the other hand increasing $L$ will enhance the assimilation process of the migrants ( $L^{\alpha}$ increases). But if $\alpha<1$ then the former effect is stronger than the latter so that as a result the local worker will his/her decrease efforts. Given this, and given the fact that $\frac{\partial a^{*}}{\partial L}>0$ if and only if $f_{L G} L^{\alpha}+\beta d c(\alpha-1)<0$ (from (9)), we see that the migrants increase their efforts to compensate for the reduction of the local population.

Another sufficient condition for an increase in the local populations' efforts to assimilate the migrants is $d<L^{\alpha-1}$ (the proof is presented in Appendix 1). The results state that if the marginal effect of $L$ local workers on the number of migrant workers is greater than one, $\alpha>1$, and the cost of investment by the local population is

$$
\begin{aligned}
&-\frac{f_{G G G} L^{\alpha-2} F^{3}}{\beta^{4}}\left[f_{L G} \alpha L(a+1)+f_{G} \alpha(\alpha-1)\left(a+b L^{\alpha}+1\right)\right] \\
&-\left[\frac{f_{L L G} L^{\alpha} F}{\beta}+\frac{f_{G G} \alpha b L^{2 \alpha-2} F^{2}(2 \alpha-1)}{\beta^{2}}+\frac{f_{G} L^{\alpha-2} F \alpha(\alpha-1)}{\beta}\right] U_{a a}^{F} \\
&+\frac{f_{L G G} f_{G G} \alpha L^{\alpha-1} F^{3}\left(a-b L^{\alpha}+1\right)}{\beta^{4}}-\frac{f_{L G} f_{G G} \alpha L^{\alpha-1} F^{2}}{\beta^{3}} \\
& \frac{\partial b^{*}}{\partial L}=-\frac{2 f_{G} f_{G G} L^{\alpha-2} F^{2} \alpha(\alpha-1)}{\beta^{3}}+\frac{f_{L G G} f_{L G} L^{\alpha} F^{2}}{\beta^{3}}+\frac{\left(f_{L G G}\right)^{2} L^{\alpha} F^{3}\left(a+b L^{\alpha}+1\right)}{\beta^{4}} \\
& H
\end{aligned}
$$


smaller than that of the migrants, $d<1$, then increasing the local population will force the migrants to divert more efforts into their assimilation activities.

Let us now consider how the cost of investing in the assimilation efforts affects those made by both parties.

We start by analyzing the increasing cost of investment made by the local population only. We thus ask what would happen if $d$ increases. The result is straightforward:

1. The investment by the migrants will increase: $\frac{\partial a^{*}}{\partial d}=-\frac{\beta^{2} c L^{1-\alpha}}{f_{G G} \alpha F}>0$.

2. The investment by the local population will decrease: $\frac{\partial b^{*}}{\partial d}=\frac{\beta^{2} c}{f_{G G} \alpha L^{2 \alpha-1} F}<0$

The results show that increasing the cost, of the local population's investment, will decrease their efforts (substitution effect). However since their efforts have decreased the migrants must increase their efforts to compensate .

Now let us analyze the position when the cost of investment increases for both parties (an increase in $c$ ):

1. The migrants investment will increase if and only if ${ }^{6} \alpha L^{\alpha-1}<d$. If the cost of the local population is greater than that of the migrants, $d>1$, and the marginal effect of $L$ local workers on the effective number of migrant workers is not higher than one, $\alpha \leq 1$ then increasing both costs will force the migrants to increase their efforts in equilibrium.

${ }_{6} \frac{\partial a^{*}}{\partial c}=\frac{L^{1-\alpha} \beta^{2}}{f_{G G} \alpha F}\left[\frac{L^{\alpha-1}\left(f_{L G G} \beta L+2 f_{G G} \alpha \beta+f_{G G G} \alpha b L^{\alpha} F\right)}{2 f_{G G} \beta+f_{G G G} F\left(a+b L^{\alpha}+1\right)}-d\right]$ thus given that the third derivatives equal to zero $f_{G G G}=f_{L G G}=f_{L L G}=0$ we get $\frac{\partial a^{*}}{\partial c}=\frac{L^{1-\alpha} \beta^{2}}{f_{G G} \alpha F}\left(\alpha L^{\alpha-1}-d\right)$. 
2. The local population's efforts will increase if and only if ${ }^{7} d<0.5 \alpha L^{\alpha-1}$.

From the results presented above, it cannot be that both parties will increase their efforts as a result of increasing costs. Moreover, increasing costs may increase or decrease the migrants' efforts as long as the local workers decrease theirs (if $d$ is "high", namely $0.5 \alpha L^{\alpha-1}<d$ ). In that case the natural effect, the substitution effect, of increasing the investment cost to the local workers would be a decrease in their efforts. However, with regard to the migrants, we get two contradicting effects. On the one hand, as shown above, increasing the cost to the local population will increase the effort of the migrants (effect 1). On the other hand, increasing the cost to the migrants will decrease their efforts (effect 2). Above, we have presented the condition which shows the effect that is stronger: if $d$ is "high enough" $\alpha L^{\alpha-1}<d$ then the increased $c$ has a "strong" effect on the cost to the local population and, as a result, the effect 1 is stronger than 2 . If $d$ is "high", $0.5 \alpha L^{\alpha-1}<d$, but not high "enough", $\alpha L^{\alpha-1}>d$, then the increased $c$ has a "weak" effect on the cost to the local population and so the effect 1 is weaker than 2 .

We consider the result of the change in the parameter $\alpha$ (the marginal effect of the local population on the assimilation of the migrants). Increasing $\alpha$ means that the local workers have a stronger impact on the assimilation of the workers into the workplace.

Increasing $\alpha$ :

1. Decreases the efforts invested by the migrants $\frac{\partial a^{*}}{\partial \alpha}<0^{8}$.

2. Has an ambiguous effect on the investment made by the local population. ${ }^{9}$

${ }_{7} \frac{\partial b^{*}}{\partial c}=\frac{\beta^{2}}{f_{G G} \alpha L^{2 \alpha-1} F}\left[d-\frac{L^{\alpha-1}\left(f_{L G G} \beta L+f_{G G} \alpha \beta+f_{G G G} \alpha b L^{\alpha} F\right)}{2 f_{G G} \beta+f_{G G G} F\left(a+b L^{\alpha}+1\right)}\right]$ thus given that the third derivatives equal to zero $f_{G G G}=f_{L G G}=f_{L L G}=0$ we get $\frac{\partial b^{*}}{\partial c}=\frac{\beta^{2}}{f_{G G} \alpha L^{2 \alpha-1} F}\left(d-0.5 \alpha L^{\alpha-1}\right)$.

${ }^{8} \frac{\partial a^{*}}{\partial \alpha}=\frac{\beta^{2} c-f_{G G} F(a+1)+\beta^{2} d c L^{1-\alpha} \ln L}{f_{G G} \alpha F}$ 
The first result shows that as $\alpha$ increases, the local population plays a stronger role in the migrants' assimilation which depend more on the local workers activities rather than those of the migrants. Thus the effectiveness of the migrant's activities decreases and, as a result, they will decrease their efforts to assimilate. The second result demonstrates, that by increasing $\alpha$, the local population, on the one hand, has to invest less, since their investment has a stronger effect, while on the other hand, each level of investment is more efficient in increasing assimilation. Therefore it is not clear which of the two effects is stronger.

\section{Concluding remarks}

In this paper we have considered the interaction between local workers and migrants in the production process of a firm. Both local workers and migrants can invest in assimilation activities in order to increase their interaction and production activities. The investment made by both type of workers increases the assimilation of the workers. Both have an incentive to invest in the assimilation process, however this causes costs on both sides.

Our study shows that increasing the number of migrants in a firm will decrease the investment of each worker, both local and migrant, in assimilation activities. We have shown some general conditions under which increasing the size of the local population in the firm will force the migrants to devote more effort to assimilation activities.

Increasing the local population's investment cost will decrease their efforts (substitution effect). However, since these efforts have decreased the migrants must increase theirs to compensate. On the other hand, it cannot be that both parties will increase efforts because of increasing costs to both local and migrant workes, in the same proportion. Moreover, increasing the cost to both parties, in the same proportion may increase or decrease efforts of migrants, as long as local workers decrease their efforts. The last result, concerning the migrants, can be explained by the following two contradicting effects. On the one hand, increasing the cost to the local population

${ }^{9} \frac{\partial b^{*}}{\partial \alpha}=-\frac{\beta^{2} c\left(d \ln L+L^{\alpha-1}\right)}{f_{G G} \alpha L^{2 \alpha-1} F}+\frac{a+1-\alpha b L^{\alpha} \ln L}{\alpha L^{\alpha}} . \frac{\partial b^{*}}{\partial \alpha}>0$ if $a+1>\alpha b L^{\alpha} \ln L$. 
will increase the migrants' efforts. On the other hand, increasing the migrants' cost will decrease their efforts. Above we have presented the condition explaining which effect is stronger.

We considered the marginal effect caused to the local population because of the assimilation of migrants, $\alpha$ - increasing the marginal affect means that the local workers have a stronger impact on the assimilation of migrants into the workplace. The first result shows that, as $\alpha$ increases, the local population plays a stronger role in the assimilation and depends more on their own activities than on those of the migrants. Thus the effectiveness of the migrants' activities decreases and as a result they will decrease their efforts to assimilate.

As seen in the paper, the structure of the firm, the number of migrants and local population are curtailed for the assimilation process. Moreover the cost of investment is an important component and can be affected by incentives made by the employer or public policy. 


\section{References}

Alesina, A. and La Ferrara E. , 2000, Participation in Heterogeneous Communities, Quarterly Journal of Economics, (August), 847-904.

Altonji, J. G. and R. M. Blank, 1999, Race and Gender in the Labor Market, in O. Ashenfelter and D.Card (eds.), Handbook of Labor Economics, vol. 3C, Elsevier Science B.V.:Amsterdam, 3143-3259.

Anas, Alex, 2002, Prejudice, Exclusion and Compensating Transfers: The Economics of Ethnic Segregation, Journal of Urban Economics, 52 (3), 409-32.

Bauer, Thomas, Gil S. Epstein and Ira N. Gang, 2005, Enclaves, Language and the Location Choice of Migrants, Journal of Population Economics, 18 (4), 649662.

Bhaumik, Sumon K., Ira N. Gang, and Myeong-Su Yun, 2006, Ethnic Conflict and Economic Disparity: Serbians and Albanians in Kosovo, Journal of Comparative Economics, 34(4), 754-773.

Blau, Francine D. and Lawrence M. Kahn, 2006, The US Gender Pay Gap in the 1990s: Slowing Convergence, Industrial and Labor Relations Review, 60 (1), 45-66.

Blau, Francine D. and Lawrence M. Kahn, 2007, The Gender Pay Gap, The Economists' Voice: Vol. 4 : Iss. 4, Article 5. Available at: http://www.bepress.com/ev/vol4/iss4/art5.

Chiswick BR, Miller PW, 1995, The Endogeneity between Language and Earnings: International Analyses, Journal of Labor Economics 13: 246-288.

Chiswick BR, Miller PW, 1996, Ethnic Networks and Language Proficiency among Immigrants, Journal of Population Economics 9: 19-36.

Chiswick, B. R., 1977, Sons of Immigrants: Are They at an Earnings Disadvantage?, American Economic Review, Papers and Proceedings, 376-380.

Constant, A., Gataullina L. and K.F. Zimmermann, 2008, "Ethnosizing Immigrants" Journal of Economic and Behavioral Organization, forthcoming.

Deutsch, Joseph, Gil S. Epstein and Tikva Lecker, 2006, Multi-Generation Model of Immigrant Earnings: Theory and Application, Research in Labor Economics, 217-234.

Dustmann, Christian, Francesca Fabbri, and Ian Preston, 2004, Ethnic Concentration, Prejudice and Racial Harassment of Minorities, CReAM Discussion Paper 05/04 (www.econ.ucl.ac.uk/cream/).

Epstein, Gil S. and Ira Gang, 2006, "Ethnic Networks and International Trade", in Labor Mobility and the World Economy Federico Foders and Rolf J. Langhammer (ed), Springer (Berlin, Heidelberg), 85-103.

Epstein, Gil S. and Ira Gang, 2009, Ethnicity, Assimilation and Harassment in the Labor Market, Research in Labor Economics, 79, 67-90.

Gang, Ira N. and Rivera-Batiz, Francisco, 1994, Labor Market Effects of Immigration in the United States and Europe: Substitution vs. Complementarity, Journal of Population Economics, 7, 157-175.

Gang, Ira N., Francisco Rivera-Batiz and, Myeong-Su Yun, 2002, Economic Strain, Ethnic Concentration and Attitudes Towards Foreigners in the European Union, IZA Discussion Paper 578 (www.iza.org). 
Gradstein, Mark and Maurice Schiff, 2006, The Political Economy of Social Exclusion, with Implications for Immigration Policy, Journal of Population Economics 19(2), 197-446.

Gradstein, Mark and Moshe Justman, 2005, The Melting Pot and School Choice, manuscript, Journal of Public Economics, 89, 871-896.

Kahanec, Martin, 2006, Ethnic Specialization and Earnings Inequality: Why Being a Minority Hurts but Being a Big Minority Hurts More, IZA Discussion Paper 2050, (www.iza.org).

Lazear, Edward P., 1999, Culture and Language, Journal of Political Economy, 107 (6, pt. 2), S95-S126.

Rapoport, H. and A. Weiss, 2003, The Optimal Size for a Minority, Journal of economic behavior and organization 52, 27-45 . 


\section{Appendix 1}

$\frac{\partial a^{*}}{\partial L}>0$ if and only if $f_{L G} L^{\alpha}+\beta d c(\alpha-1)<0$. Let us calculate the last expression using the first order conditions

$$
U_{a}^{F}=\frac{f_{G}}{\beta}+\frac{f_{G G} F\left(a+b L^{\alpha}+1\right)}{\beta^{2}}-c=0
$$

and

$$
U_{b}^{L}=\frac{f_{L G} L^{\alpha} F}{\beta}+\frac{f_{G} \alpha L^{\alpha-1} F}{\beta}+\frac{f_{G G} \alpha b L^{2 \alpha-1} F^{2}}{\beta^{2}}-d c F=0
$$

From (A1) we get:

$$
f_{G}=\beta c-\frac{f_{G G} F\left(a+b L^{\alpha}+1\right)}{\beta}
$$

and from (A2) we can extract the expression $f_{L G} L^{\alpha}+\beta d c(\alpha-1)$ :

$$
f_{L G} L^{\alpha}+\beta d c(\alpha-1)=\alpha\left(\beta d c-f_{G} L^{\alpha-1}-\frac{f_{G G} b L^{2 \alpha-1} F}{\beta}\right)
$$

Substituting $f_{G}$ into the last equation:

$$
\begin{gathered}
f_{L G} L^{\alpha}+\beta d c(\alpha-1)=\alpha\left\{\beta d c-\left[\beta c-\frac{f_{G G} F\left(a+b L^{\alpha}+1\right)}{\beta}\right] L^{\alpha-1}-\frac{f_{G G} b L^{2 \alpha-1} F}{\beta}\right\} \\
f_{L G} L^{\alpha}+\beta d c(\alpha-1)=\alpha\left\{\beta d c-\beta c L^{\alpha-1}+\frac{f_{G G} L^{\alpha-1} F(a+1)}{\beta}\right\}
\end{gathered}
$$

Since $f_{G G}<0$ we can see that $f_{L G} L^{\alpha}+\beta d c(\alpha-1)<0$ (which is equivalent to $\left.\frac{\partial a^{*}}{\partial L}>0\right)$ if $\beta d c-\beta c L^{\alpha-1}<0$ which is the same condition as $d<L^{\alpha-1}$. 